\title{
Indagando en los Silencios del Franquismo: Carta de una Mujer Ingresada en un Manicomio de Gipuzkoa
}

\author{
ITXASO MARTIN ZAPIRAIN* \\ Universidad del País Vasco (UPV/EHU), San Sebastián, Spain
}

\begin{abstract}
Breaking the social rol has, almost always, consequences. That is the case of Carole, a woman who has been hospitalized in a psychiatric institution in Gipuzkoa between 1949 and 1950. Carole was Belge and she highlighted explicitly the characteristics of Franco's regime. Based on a letter she wrote during her hospitalization and on her medical report, this article composes an image of the morality and the society in that time in the southern Euskal Herria. Furthermore, through an analysis of an individual case, not only silences and repression will surface but also the resistances.
\end{abstract}

Keywords: "Mad" women, Euskal Herria, Franco's regime.

Resumen. Salirse del rol que marca la sociedad y la moral de cada época casi siempre tiene sus consecuencias. Ese es el caso de Carole, una mujer que estuvo ingresada en un psiquiátrico de Gipuzkoa durante los años 1949 y 1950. Carole era belga y mostrará de forma explícita las características del régimen franquista. Basándome en una carta que ella misma escribió y en las notas recogidas en su

\footnotetext{
* Author's address:

Departamento de Filosofía de los Valores y Antropología Social

Universidad del País Vasco (UPV/EHU)

Goiko Galtzada Berri 2, 1.A, 20009 Donostia-San Sebastián, Gipuzkoa, Spain

E-mail itxaso.martin@ehu.eus
} 
informe clínico, compondré una imagen de la moral y la sociedad que se vivía en aquella época en las cuatro provincias del sur de Euskal Herria. Además, partir de un solo caso, permite sacar a la luz no solo los silencios y las represiones que las mujeres consideradas locas sufrían, sino también sus resistencias.

Palabras clave: Mujeres "locas", Euskal Herria, régimen franquista,

\section{La Carta}

\section{"Dear Sir;}

I haven't seen you for ages but I hope you are fine and prosperous. The other day you had the kindness to ask me where I wouldn't like to live and after careful analyse of my tragic situation, because of my ruined health, there are but two solutions with which I agree plainly. May I please explain to you my wishes and ask for your help and approbation to fulfill them. My health here is every day worse and I wish to leave this country as soon as possible. No human thinking person of my nationalitiy could ever stand such a coercion of ideas and religion. Remember I am no catholic I consider my life here as illegal prison and I beg my powerful friends and my only beloves and respected Son $[. . .]^{2}$ to help me away from it. In his last letter he informed me about his intention to visit me by now, about the end of this year in Suresnes. Remember that I have been transferred here against my will and by brutal force. Nevertheless in Suresnes I have been healthy my body respected and in a certain way happy. If my Monsieur [...] would care to have me back there which I suppose not it would be a pleasure to me. I promise to behave nicely and I always keep my promises. This letter by itself gives a fair concept of it. I have been betrayed a friendship and my devotion to him was of the very best kind. Once again the will have to decide for I suppose he still might have an interest in me. If this idea is absurd and a mere illusion it is much justified for I can't withdraw a sincere interest a beautiful sentiment developed and intensified during this months like one withdraws an old suit. I belong to a country where private sentiments and private lives are not an utopie. Supposing Monsieur [...] decides to bring me

${ }^{2}$ Debido a la confidencialidad, a partir de ahora utilizaré nombres inventados o dejaré huecos para sustituirlos. 
back to Paris there are some considerations for any reasonable order of $M[\ldots]$ will always be accepted and respected by me. I shall not be treaten like a prisoner without light and fresh air for I want to live a normal life, writing, reading, working and so on. The food and the service will be good there as usual. Monsieur [...] will kindly claim in certain amount of my money for I need to buy clothes and everything I need and want to make life agreable and be myself once again. I wont't trouble. Here I have acquired some interesting deductions but I am not disposed to carry with the sins of other people and if ever I meet again Madame [...] or any one who cares to discros any matter old or new with me, I feel quite at case to tell them some ${ }^{3}$ truth. We are going to set every person in the right place and mine shall be a first class one. My innocence has come to an end. It has not paid me to be so good. Let's try something different. My respect and admiration for the gentleman to whom I write this letter is sincere. I hope he will help me. The other solution for me is that Don $[\ldots]^{4}$ shall keep his promise and bring me alive and safely to Portugal. Once there I would like to continue my journey to New York. In the U.S I used to have some first class friends. I love the American way and I would love to work over there I feel sure My American friends will not abandon me and may be they could restore my broken health. I have such a good right and such a sincere desire to live and to be a constructive part of this world. With hope and best love I consider myself affectionately yours ${ }^{56 "}$.

${ }^{3}$ Cuando utilizo la barra baja significa que hay una palabra que no he conseguido entender.

${ }^{4}$ Menciona un importante mandatario de la época.

${ }^{5}$ La carta está reproducida literalmente. La escribió una mujer (Carole) que estuvo ingresada durante 9 meses en un manicomio de Gipuzkoa, el 7 de noviembre de 1949

${ }^{6}$ Estimado Señor; hace tiempo que no nos hemos visto pero espero se encuentre bien y próspero. El otro día tuvo la amabilidad de preguntarme dónde no me gustaría vivir y después de un minucioso análisis de mi trágica situación, debida a mi ruinosa salud, solo hay dos soluciones con las que estoy plenamente de acuerdo. A continuación, ruego déjeme explicarle mis deseos y le pido ayuda y aprobación para cumplirlos. Mi salud aquí empeora cada día y deseo dejar este país tan pronto como sea posible. Ninguna persona que piense humanamente y de mi nacionalidad podría soportar esta coerción de ideas y religión. Recuerde que yo no soy católica y considero mi vida aquí como prisión ilegal y ruego a mis 
Encontré esta carta en el archivo de un psiquiátrico ${ }^{7}$ de Gipuzkoa donde realicé parte de la investigación de la tesis doctoral ${ }^{8}$. La autora de la misma,

poderosas amistades y mis seres queridos y respetado Hijo [...] que ayude a salir de aquí. En su última carta me informó sobre su intención de visitarme pronto, a final de este año en Suresnes. Recuerde que he sido trasladada en contra de mi voluntad y forzosamente. Sin embargo, en Suresnes he estado sana, mi cuerpo ha sido respetado y en cierta medida feliz. Si a mi Señor [...] le importaría tenerme de vuelta, lo que supongo que no, sería un placer para mí. Le prometo que me comportaré bien y siempre cumplo mis promesas. Esta carta por ella misma supone una claro ejemplo de ello. He sido traicionada por una amistad y mi devoción hacia él era buena. Una vez más, deseo decidirá por lo que supongo que él sigue teniendo un interés en mí. Si esta idea es absurda y una mera ilusión estaría justificada porque no puedo desechar un sincero interés como se desecha un viejo traje. Pertenezco a un país en el que los sentimientos privados y las vidas privadas no son una utopía. Suponiendo que el Señor [...] decide llevarme de vuelta a París hay algunas consideraciones por órdenes razonables del Señor [...] que van a ser siempre aceptadas y respetadas por mí. No sería tratada como una prisionera sin luz ni aire fresco porque quiero vivir una vida normal, escribiendo, leyendo, trabajando y todo eso. La comida y el servicio serán buenos allí, como siempre. Pediría amablemente al Señor [...] algo de dinero porque lo necesito para comprar ropa y todo lo que necesito y quiero para hacer mi vida más agradable y volver a ser yo misma otra vez. No crearé problemas. Aquí he llegado a interesantes deducciones pero no estoy dispuesta a acarrear con los pecados de otras personas y si algún día vuelvo a encontrarme con Madame [...] u otra persona que vaya a sacar un tema viejo o nuevo conmigo, me sentiré en la situación de tener que decirles algunas verdades _. Pondremos a cada persona en el sitio que le corresponde y el mío será de primera clase. Mi inocencia ha llegado a su fin. No he sido pagada para ser tan buena. Intentemos algo diferente. Mi respeto y admiración hacia la persona a la que escribo esta carta es sincero. Espero él me ayude. La otra solución para mí es que Don [...] mantenga su promesa y me llegue viva y a salvo a Portugal. Una vez allí me gustaría continuar con mi viaje a Nueva York. En EEUU he tenido amigos de primera clase. Adoro la forma de vivir americana y adoraría también trabajar allí. Estoy segura de que mis amistades americanas no me abandonarán y puede que puedan restaurar mi estropeada salud. Tengo derecho y sincero deseo de vivir y de ser parte constructiva de este mundo. Con esperanza y sincero amor me considero afectuosamente suya".

${ }^{7}$ Hice análisis de archivo durante cuatro meses, entre noviembre de 2012 y febrero de 2013.

8 Tesis titulada: Eromena, azpimemoria eta isiltasuna(k) idazten: hutsune bihurtutako emakumeak garaiko gizartearen eta moralaren ispilu y realizada con la ayuda del programa predoctoral del Gobierno Vasco (2012-2015). 
Carole $^{9}$, la escribió el 7 de octubre de 1949. La carta estaba dentro del informe clínico de Carole y, por lo tanto, no fue enviada a su destinatario. Partiendo de ese punto y basándonos en el texto escrito por ella, el objetivo de este artículo es llegar a analizar la sociedad y la moral de aquella época desde una perspectiva de género.

La elección de la carta de Carole no es aleatoria. En la propia carta se puede leer que ella era de otro país, de Bélgica concretamente; por lo tanto, la información que ella nos proporcionará sobre Hego Euskal Herria ${ }^{10}$ cobrará una especial relevancia. La mujer que escribió esta carta vivió ciertas situaciones que consideraba extrañas ${ }^{11} \mathrm{y}$, por lo tanto, proporcionará información relevante sobre ciertas situaciones y cosas que las personas autóctonas tenían interiorizadas. Carole era una mujer que viajaba mucho, demostrando capacidad para plantear diferencias entre unos lugares y otros: "I love the American way and I would love to work over there". Tenía amistades en New York y quería viajar allí, pues se sentía atraída por su forma de vivir. Por lo tanto, tuvo la oportunidad de conocer que la sociedad y la moral de cada lugar eran diferentes, obteniendo la capacidad de comparar e identificar las características de la vida que, en ese sentido, se vivía en Hego Euskal Herria.

\section{Partiendo de un Solo Caso}

Las historias individuales nos dan información valiosa sobre el contexto. Colocar casos concretos en el punto de partida de la investigación ayuda a que los individuos no queden disueltos o difuminados en el contexto, y eso nos proporcionará ciertas ventajas, una de ellas es la posibilidad de poner de relieve la agencia o la resistencia que llevan a cabo esas personas.

En general, es a través de la biografía como se sacan a la luz casos concretos. De esa manera, una sola persona es la base de la investigación y se intenta proporcionar la máxima cantidad de datos e información sobre ella; es decir, se trata de compensar la utilización de un solo caso con la cantidad de información que se de él. La biografía es utilizada como la técnica por excelencia para aflorar voces silenciadas o historias desconocidas, es el caso de

${ }^{9}$ El nombre es ficticio.

${ }^{10}$ Hego Euskal Herria (Sur de Euskal Herria) incluye las provincias de Gipuzkoa, Bizkaia, Álava y Navarra.

${ }^{11}$ Referente a que no pertenecían al contexto que se vivía en su país. 
Lisa Appignanesi (1990), que propone hacer la investigación feminista de la psiquiatría a través de las historias de mujeres consideradas locas: "Los casos dan luz. Son ellos los que nos ayudan a sacar las interacciones que existen entre la cultura, la práctica psiquiátrica y la enfermedad en cada momento histórico concreto"12 (Appignanesi 2008: 9). Para Appignanesi, las historias individuales son imprescindibles si nuestro objetivo es obtener información sobre el contexto. Pero ¿qué ocurre cuando somos conscientes de que un caso nos va a proporcionar información importante sobre el contexto pero no podemos acceder a él? Precisamente es habitual encontrarnos con esa situación cuando hablamos de personas que han sido marginadas, como es el caso de las mujeres ingresadas en psiquiátricos.

Una manera de darle una solución al problema ahora mencionado es lo que Ignasi Terradas i Saborit llama antibiografía. Terradas denomina antibiografía al vacío o negación biográfica y, en su opinión, es a través de ese vacío o esa negación como sabremos el trato que una civilización concreta le ha dado o le está dando a los individuos marginados. Por lo tanto, la antibiografía podrá ser utilizada para saber más sobre las personas que menos visibilidad han adquirido o adquieren en la sociedad:

Si recorremos ese trayecto a la inversa, podemos caer en la cuenta de lo mucho que ha tenido que hacer una civilización para alcanzar esa irreductibilidad en la vida de una persona [...] Es el poder de los márgenes en la vida social (Terradas 1992: 13).

En la cultura antibiográfica, se ensalza pero, a la vez, se rechaza a la persona; se la tiene en consideración pero, a la vez, se le da importancia a que esa persona no haya sido tenida en cuenta. Lo que se propone no es una recopilación de datos de la persona en concreto, sino lo que nos da el no tener datos. De esta forma, a través de la antibiografía, quedará en evidencia la necesidad que tiene la sociedad de esas personas que ha marginado, pues es en base a lo que deja en los márgenes como la sociedad construye las características de lo que está dentro de los límites: "La manera como puede llegar"13 a ser tratada una persona en el tiempo y en el espacio de una sociedad es la manera reservada para todos los demás" (Terradas 1992: 41). Siguiendo lo que Terradas plantea, aunque la información de lo que se margina no sea considerada como

\footnotetext{
${ }^{12}$ El original está en inglés, la traducción es mía.
}

${ }^{13}$ La cursiva es suya. 
referencia, funciona como tal; se facilita información de lo que se margina en gran medida porque, de esa forma, se le estará enseñando al resto de miembros de la sociedad que adquirir cierto tipo de conductas podrá llevarlos a ser marginados.

\section{La "Antibiografía" de Carole}

En el caso de la mujer que estamos analizando se cumplen las condiciones que menciona Terradas: disponemos de poca información y es una mujer que podemos situar en los márgenes de la sociedad, considerada loca e ingresada durante 9 meses en un manicomio. Para hacer la antibiografía de Carole me basaré en la información del informe médico encontrado en el archivo de un psiquiátrico de Gipuzkoa. En su historia médica hay textos escritos por médicos, enfermeras, o por ella misma. Considero que de todos esos documentos el más significativo es una carta que escribió, la cual he utilizado para comenzar el artículo. Es importante destacar que la carta estaba dirigida a un amigo y ella pensaba que la escribía para ser enviada, pero en muchos casos las cartas escritas por las personas ingresadas eran leídas por los responsables del psiquiátrico y se introducían en la historia clínica sin ser enviadas. Por lo tanto, esto nos lleva a pensar que, probablemente, Carole escribió la carta sin ningún "filtro", pensando que la única persona que la iba a leer era su destinatario.

Ingresaron a Carole el 24 de junio de 1949, y estuvo ingresada hasta el 31 de marzo de 1950, 9 meses y 7 días en total. Tenía 46 años cuando la ingresaron. Había nacido en Bélgica y sus padres eran aristócratas. Se casó dos veces, la primera en Bélgica y la segunda en España. Hay que tener en cuenta que, en aquella época, en el Estado Español no se barajaba la posibilidad de divorciarse; por lo tanto, la situación de Carole era considerada, ya por ese hecho, especial. El divorcio se tomaba como ejemplo de su comportamiento (llegando a ponerse en duda una y otra vez lo adecuado del mismo). Con el primer marido tuvo un hijo, precisamente habla sobre él en la carta y menciona que a finales de año la iba a visitar "In his last letter he informed me about his intention to visit me by now, about the end of this year". El segundo marido era diplomático y tuvieron dos hijas. Era habitual que, nada más ser ingresadas en el psiquiátrico, los médicos escribieran un informe sobre ellas y esta es la descripción que el psiquiatra hizo de Carole: 
Casó muy joven con su primer marido del que tuvo un hijo. Pronto el matrimonio fue mal. Después enseguida casa con su segundo marido del que tiene 2 hijas. También pronto disensiones matrimoniales originadas por la tendencia al gasto, incapacidad de administración y carácter de la enferma ${ }^{14}$.

Tomando en consideración lo que el médico dice en esa nota, podemos concluir que hizo responsable a Carole y al carácter que ésta tenía de la situación matrimonial. Más adelante, el psiquiatra escribió que la mujer que acababa de ingresar tenía relaciones sexuales extramatrimoniales. Esta última mención llama la atención poderosamente puesto que, en el caso de las mujeres, el apartado referido a las relaciones sexuales ${ }^{15}$ no se rellenaba prácticamente nunca (en el caso de los hombres, sin embargo, era habitual que escribieran en él). Hay que añadir, además, que en los informes de mujeres, en los casos en los que el apartado de relaciones sexuales estaba relleno, las referencias solían estar relacionadas con la menstruación y/o con comportamientos que se consideraban enfermizos, como el "exceso" de masturbación. En el caso de Carole, uno de los síntomas de su "enfermedad mental" eran sus relaciones extramatrimoniales, que eran prueba de un comportamiento que no correspondía a las mujeres.

Era habitual también que en el informe de ingreso se recogiera la opinión de la familia: se les preguntaba sobre la persona que iba a ser ingresada y se anotaba su respuesta. En este caso, no se concreta quién es la persona que proporcionó la información, pero el familiar que fue preguntado sobre ello describió de la siguiente manera la situación:

Hace 7 años estaba en Estados Unidos y le hicieron venir diciendo que su marido estaba enfermo para reintegrarle en su familia y evitar el tipo de vida que hacía. Hace 4 años, estando en Biarritz con sus hijos hubo que dar la administración al tutor por desastre. Comenzó con un delirio de persecución a base de falsas interpretaciones por las que le acusaban de mala madre, mala esposa, y que consiguieron con estas calumnias apartarle de sus hijos, deshacer su hogar y robarle su dinero. Hace 7 meses estaba sola en Paris y fue internada por

${ }_{14}^{14}$ Las citas del informe médico están copiadas literalmente.

${ }^{15}$ En los informes de admisión había expresamente un apartado dedicado a las relaciones sexuales. 
orden policiaca a causa de los escritos, protestas y escándalos. Estuvo ingresada en Suresnes donde no le han hecho ningún tratamiento.

Antes de ser hospitalizada en el psiquiátrico de Gipuzkoa, Carole fue ingresada en otra institución psiquiátrica, y ella misma relata su traslado de la siguiente manera: "Remember that I have been transferred here against my will and by brutal force". En contra de su voluntad y a la fuerza, es como describe la forma en la que la trasladaron de Suresnes a Gipuzkoa. En muchas ocasiones, en este tipo de situaciones se les administraban calmantes para ingresarlas; no podemos saber si a Carole le introdujeron alguna medicina, pero de sus palabras se puede entender que opuso resistencia. Otra conclusión que podemos sacar de sus palabras es que se sentía mejor en Suresnes, y que el hecho de sentirse mejor lo relacionaba directamente con la ausencia de tratamiento: "Nevertheless in Suresnes I have been healthy my body respected and in a certain way happy". Hay que tener en cuenta que, en esta época, los tratamientos eran llevados a cabo con la intención de influir en el propio cuerpo; la locura, o como en la época se denominaba, la "enfermedad mental", se relacionaba con alguna "anormalidad" que el propio cuerpo tenía (genética en la mayoría de los casos). En el psiquiátrico de Gipuzkoa Carole fue tratada con electroshocks y comas insulínicos ${ }^{16}$ y estaría haciendo referencia a ellos cuando dice que en Suresnes su cuerpo fue respetado. A esa idea hay que añadirle que el propio médico admite que: "Estuvo ingresada en Suresnes donde no le han hecho ningún tratamiento".

Una muestra de la dureza del tratamiento que sufrió Carole es que estaba aterrorizada por los electroshocks y los comas insulínicos. Las propias enfermeras dicen que sentía un gran rechazo y que desconfiaba de todo lo que se

${ }^{16}$ Provocaban comas hipoglucémicos inyectando insulina. Es una técnica que Sakel utilizó por primera vez en 1927. En el psiquiátrico de Gipuzkoa la utilizaron entre los años 1937 y 1967. "A veces se inyectaba insulina solo para conseguir relajación sin llegar al coma. El paciente estaba en su habitación y por la mañana, en ayunas, le inyectaban insulina en el brazo o en la pierna, le controlaban y cuando entraba en coma hipoglucémico ( 2 ó 3 horas tras la insulina) le introducían una sonda nasogástrica, aspiraban el jugo para saber que no estaban en pulmón, y le administraban una solución de $200 \mathrm{~g}$ azúcar en agua o leche, o miel [...] El paciente volvía a tardar 1 ó 2 horas en cobrar plenamente la consciencia [...] A veces le aplicaban electroshock mientras el paciente estaba inconsciente. Unos pacientes pasaban lentamente del sopor al coma, y otros tenían sudoración y convulsiones con apnea" (López Velasco 2010:103). 
le daba. Parece ser que habló sobre el tratamiento con una de sus hijas y le rogó que pidiera se lo quitaran. Su hija hizo lo que Carole le pidió tal y como podemos deducir de una de las cartas que el médico dirigió a ésta:

Cuando en el mes de Agosto hicimos el tratamiento que se interrumpió a causa de las órdenes de Uds la situación de la enferma había variado en el sentido de mejoría de todos sus síntomas y una mejor sociabilidad. Si hubiéramos continuado con el tratamiento es de esperar que la situación actual de su madre fuera completamente diferente; pues se hubiera detenido el curso de su enfermedad o esta habría remitido. Con estas condiciones creo mi deber solicitar de Ud. una autorización para comenzar nuevamente un tratamiento a su madre ${ }^{17}$.

Para entender esto es necesario especificar que el psiquiátrico de Gipuzkoa del que hablamos era privado en aquella época. "We are going to set every person in the right place and mine shall be a first class one", dice Carole. Ingresaban a gente rica y como era la familia la que pagaba la estancia, se tenía muy en cuenta lo que los miembros de la misma decían. Es en ese contexto donde tenemos que entender, por lo tanto, que el médico siguiera las instrucciones de la hija y anulara el tratamiento, por lo menos durante un tiempo.

El 28/29 de julio de 1949, Carole continuó contando su historia y en el diario que las enfermeras escribían sobre cada una de las personas ingresadas anotaron lo siguiente:

Yo vivía muy feliz con ellas pero una mano negra, ese nombre solamente se le puede dar a esa persona, me las arrancó de mi lado cuando todavía eran unas niñas que necesitaban mucho de su madre. Si a usted que es una persona buena y bondadosa le obligan un día a que deje todo esto y quien manda hacer esto es nada menos que todo un Cónsul de cierto país. ¿Qué haría? Lo que yo he hecho ¿No es cierto? Doblegarme y esperar a que llegue el día que usted pueda hablar ¿Verdad? Pues eso me pasa a mí. Que adelantaría si yo me opusiera y me volviera rebelde a todo esto. Creo que no adelantaría nada con esa aptitud. Es mejor esperar. Ese día estoy dispuesta a pegarme incluso con ese vil que ha destrozado estos años de mi vida ${ }^{18}$.

\footnotetext{
${ }_{17}$ Carta que el médico dirigió a la hija de Carole incluida en el informe clínico.

18 Nota escrita en el diario por las enfermeras.
} 
Carole sabía qué actitud debía tomar para acabar con su encierro. Era consciente de que las cosas que hacía no estaban bien vistas y sabía que revelarse ante lo que le estaban haciendo no le iba a reportar ningún beneficio, no si su objetivo era salir de donde estaba. Sabía de quién había sido la decisión de encerrarla en el psiquiátrico y sabía que tendría que "doblegarse" si quería salir de allí. De todas formas, ella misma aceptaba que era una actitud que iba a tener que tomar durante un tiempo, pues indicó que al salir del manicomio tenía intención de hacerle frente a "esa mano negra".

Las personas ingresadas recibían visitas de vez en cuando y las enfermeras tomaban nota de ellas en los diarios. En el cuaderno de la mujer que estamos estudiando, la primera vez que se menciona una visita es del 7 al 15 de septiembre de 1949 (para entonces llevaba ingresada casi tres meses). La enfermera, aparte de la visita, anotó también lo que dijo Carole sobre la misma y su reacción posterior:

Tiene visita. "Estoy muy contenta me ha venido a visitar Don $[\ldots]^{19}$ me ha prometido sacarme de esta casa y como no espero que este Sr me va a decir mentira tengo mi equipaje todo preparado..." Como pasa más tiempo de lo que esperaba de que vendrían a buscarla esta de mal humor ${ }^{20}$.

Queda en evidencia el deseo que tenía de salir del psiquiátrico. Preparó la maleta en más de una ocasión, siempre pensando que había llegado el día en que iban a sacarla de allí. Esperaba días pero, pasado un tiempo, cuando veía que nadie aparecía, se enfadaba. En el propio diario se ve que la necesidad que tiene de salir del psiquiátrico era cada vez mayor:

Habla sola constantemente y por las noches cuando despierta llama a personas imaginarias pidiendo que le saquen cuanto antes de la prisión en la que le tienen encerrada. Habla francés e inglés ${ }^{21}$.

Es importante mencionar que la carta que escribió Carole pidiendo ayuda a su amigo (extranjero) fue escrita el 7 de noviembre de 1949; para esa fecha, en su diario, ya se había relatado un primer intento de fuga:

$\overline{19}$ Menciona un familiar muy cercano de Francisco Franco, detallando la relación familiar que los une. Es una nota escrita por las enfermeras en el diario.

${ }^{20}$ Nota del diario escrita por las enfermeras.

${ }^{21}$ Nota escrita por las enfermeras entre el 11 y el 16 de noviembre de 1949. 
${ }^{22}$ Por la tarde a la hora del reposo baja al entresuelo al parecer con la intención de escaparse cierran todas las puertas cuando las Srtas [...] e [...] le ordenan suba a la habitación se niega y como le obligan a meterse en la cama y le quitan la ropa les insulta y le pega a la Srta [...] como esta excitada por orden del Dr se le inyectan 2cc de Brom-Hioscin ${ }^{23}$.

Las llamadas de ayuda no daban frutos y los enfados iban en aumento. Creía que su hijo iba a ir a visitarla, pero no se hizo referencia alguna a esa visita en el diario. Las referencias que hacía sobre sus familiares eran amables durante los primeros meses pero, llegado diciembre, (llevaba ingresada casi seis meses) rechazó una carta de su hija: "Recibe carta de su hija le entrego y sin mirar de quien es la rompe hace un gesto despreciativo y me la entrega sin mediar palabra" 24 . Según la enfermera, Carole tiró la carta sin saber de quién era; por lo tanto, podemos pensar que la consecuencia de que sus llamadas de auxilio cayeran en saco roto hizo que se enfadara con todos/todas los que estaban "fuera".

Llama poderosamente la atención que, a partir de mediados de diciembre, las notas en su diario empezaron a ser cada vez más escasas. Las enfermeras subrayaban que su comportamiento era correcto y estaba bien integrada en la institución. Hubo un gran cambio, pero es imposible saber, por lo menos con los documentos encontrados en su historial médico, cuál fue la razón del mismo. Las enfermeras escriben que dormía muy bien, que estaba tranquila y que diariamente le dedicaba un tiempo a la lectura. En enero de 1950 no escribieron ni una sola nota, en febrero hay una y dos en marzo, cuando estaba a punto de salir del psiquiátrico. De todo esto podemos suponer que las enfermeras consideraron que no había nada mencionable en su comportamiento y, por lo tanto, que Carole estaba siguiendo adecuadamente el ritmo del psiquiátrico y, como ella misma decía, no se estaba "revelando". Así, el 31 de marzo de 1950 le dieron el alta y, según las enfermeras, recibió la noticia muy contenta. Esta es la última nota del diario:

Por la mañana se levanta está muy cariñosa y pide el desayuno con mucha amabilidad se arregla temprano y prepara su equipaje con

\footnotetext{
${ }^{22}$ Nota del diario.

${ }^{23}$ Butilbromuro Hioscina, substancia utilizada para evitar espasmos.

${ }^{24}$ Nota escrita por las enfermeras entre el 22 y el 26 de diciembre de 1949.
} 
ayuda de la Srta [...] Por la tarde después de comer vienen a buscarle y sale definitivamente ${ }^{25}$.

Carole murió en París, tenía 81 años.

\section{Construyendo el Contexto}

En la década de 1940, el régimen de Franco tenía poder e influencia sobre Hego Euskal Herria y, por lo tanto, el modelo de ujer $^{26}$ que proponía la dictadura franquista era aplicable también a ese territorio. La primera mitad del siglo XX fue una época paradójica para las mujeres; durante la Segunda República hubo avances respecto a su situación jurídica y social, pero durante la Guerra Civil y el Franquismo, todos esos cambios fueron anulados: "se suprimió la escuela mixta, se prohibió el trabajo nocturno a mujeres, se 'liberó' a la mujer casada 'del taller y de la fábrica"' (Moraga 2008: 232). El fascismo ensalzó la maternidad y la sumisión de la mujer. La política que impulsaba la maternidad tenía dos objetivos principales: por una parte, intentaba limitar a la mujer al ámbito privado y, por otra, convertir el Estado Español en un territorio que tuviera poder internacional. Durante la época conocida como el Primer Franquismo (1939-1959), el régimen hizo grandes esfuerzos para establecer un nuevo sistema de género.

La dictadura impuso un modelo de mujer muy cerrado y muy concreto. La mujer debía ser sumisa, casera, católica y cuidadora, e intentaban meter a las mujeres que no cumplían con esas características dentro de las mismas y, para ello, se utilizaron todo tipo de fuerzas y coerciones. La institución eclesiástica jugó un papel muy importante en la difusión y la imposición de ese modelo. Carole misma señaló en su carta la fuerza que tenía la religión católica: "My health here is every day worse and I wish to leave this country as soon as possible. No human thinking person of my nationalitiy could ever stand such a coercion of ideas and religion. Remember I am no catholic". Utiliza la palabra coerción haciendo una comparación con la situación que se vivía en su país natal, Bélgica. Fue la Iglesia Católica la que escribió los libros que las mujeres tenían que utilizar en la escuela y, a través de ellos, se estableció una construcción ultraconservadora de la feminidad "ideal", que

${ }_{25}$ Nota del 31 marzo de 1950.

${ }^{26}$ Escribo mujer en cursiva para subrayar que está en singular, pues me refiero al modelo único de mujer del que se hablaba en esa época. 
vería a la mujer como la cuidadora principal de la estabilidad social (Graham 2010: 182). La ley decía lo siguiente:

El único matrimonio valido era el canónico, ya que el civil pasaba a ser considerado como "desagravio a la conciencia católica de los españoles" (art. 42); la única manera de romper un matrimonio era como consecuencia de la muerte de uno de los cónyuges (art. 52); la mujer quedaba sometida a una absoluta dependencia ("el marido es el administrador de los bienes de la sociedad conyugal", art. 59, y "el marido es el representante de su mujer", art. 60) y obediencia al marido ("el marido debe proteger a la mujer y esta obedecer al marido", art. 57); según el artículo 237 eran consideradas personas "inhábiles", igualándolas a menores o dementes; y el artículo 320 establecía en 21 años la mayoría de edad de las mujeres (Ruiz 2009: 19; in Abad, 2009: $73)$.

Pero sin la necesidad de las leyes, el régimen franquista demostró la fuerza que puede llegar a tener un discurso. En este sentido, la imposición del nuevo sistema de género se hizo, en gran medida, a través de la Iglesia Católica y la Sección Femenina de la Falange (Altuna y Aranburu 2012). Las dos instituciones controlaron a las mujeres, sobre todo en torno a dos temas: la maternidad y la sexualidad. Impusieron un control y juicio exhaustivo sobre esos dos ámbitos. La Iglesia Católica y la Sección Femenina de la Falange alimentaban la ideología del régimen y castigaban todas aquellas actitudes que no comulgaban con lo que ellas planteaban. La Iglesia Católica utilizó la confesión como medida de control e identificación de las mujeres que tenían pensamientos que las llevaban a tener actitudes "inadecuadas". Carole se quejaba continuamente de que en el propio manicomio le pedían que contara todo lo que sentía: "I belong to a country where private sentiments and private lives are not an utopie". Ella no quería contar ciertas cosas, y como le obligaban a hacerlo, comparaba lo que tenía que hacer en el psiquiátrico de Gipuzkoa (confesarse una vez a la semana) con la situación que anteriormente había vivido en Bélgica. Como he mencionado antes, ella sabía que su comportamiento no estaba bien visto a los ojos de las personas que la rodeaban; por lo tanto, la confesión servía para que fuera juzgada más de lo que ya era. Al fin y al cabo, utilizaban lo que las mujeres contaban durante sus confesiones 
para reafirmar su "enfermedad mental""27 (de la misma manera que lo hacían con la correspondencia que escribían).

Esta mujer fue juzgada por sus relaciones sexuales y por su forma de llevar a cabo la maternidad. Ella misma decía que le habían quitado a sus hijas y hacía responsable de todo ello a un hombre. Concretamente, el franquismo hizo grandes esfuerzos para controlar las prácticas sexuales de las mujeres e impuso normas basadas en el tradicionalismo y el catolicismo. El deseo sexual de las mujeres era considerado como algo patológico, y más en el caso de Carole, que tal y como se detalla en su informe clínico, mantenía relaciones extra-matrimoniales. Las mujeres en esta época, tenían que limitar sus relaciones sexuales a la reproducción. De esta manera, se marcaba cómo tenía que ser la maternidad, que fue marcada por la religión católica y adoptada por la psiquiatría de la época. Así describía Mercedes Suárez-Valdés, representante de la Sección Femenina, a la madre ideal en el libro La madre ideal escrito en 1951:

El tipo de madre ideal es para casi todo el mundo la madre que se desvela por sus hijos desde que nacen, consagrándose a su cuidado, los cría y los atiende por sí misma, sacrificándolo todo, y luego los forma moral y espiritualmente, haciendo de ellos hombres y mujeres honrados, rectos, cristianos y patriotas (Suárez en González Pérez 2009:98).

Todo comportamiento que se situara fuera de ese modelo de maternidad se consideraba enfermedad. Si seguimos el informe de Carole, podemos comprobar que no cumplía con las características de la madre modelo que planteaba Suárez-Valdes: viajaba sola, estaba divorciada, se dice que tenía tendencia al gasto y no era católica. El propio psiquiatra dice que: "Hace 4 años, estando en Biarritz con sus hijos hubo que dar la administración al tutor por desastre".

Tal y como se ha descrito, la psiquiatría de la década de 1940 siguió los principios morales de la religión católica y presentó a la mujer como un ser al que había que controlar muy especialmente: "Vigílese el trabajo de la mujer, máxime en la infancia, pubertad, embarazo y lactancia" (Echeverría 1948: 193). La misoginia de muchos de los textos psiquiátricos de la época mostró

${ }^{27}$ En los documentos del informe clínico no se menciona el diagnóstico que se le hizo a Carole. 
que la normalidad masculina estaba basada en la construcción de la anormalidad femenina (Medina 2013: 71). En ese sentido,

la medicina puso la ciencia al servicio de la defensa del orden patriarcal [...] emprendió la tarea de demostrar científicamente que la especificidad fisiológica del sexo femenino llevaba consigo una especialización mental (Barrachina 2003: 69).

A lo señalado hasta ahora en este apartado hay que añadir el pecado y la culpabilidad. Es decir, el no seguir el modelo que el régimen marcaba no conllevaba solo el castigo por parte de las instituciones, sino que también incluía la que una misma se infligía: la culpabilidad y el pecado. Éstos son conceptos que han sido especialmente desarrollados por la religión católica, y habría que subrayar que, sobre todo, se adjudicaban a las mujeres. Para la religión católica, la "esencia" del ser humano era pecadora, y durante el franquismo era la mujer la que se vinculaba a ello, sobre todo, y la que, por lo tanto, tenía que hacerle frente a ello (Piérola 2000: 45).

\section{La Resistencia de Carole}

El franquismo, al ser un régimen fascista, planteaba un solo modelo para todo: en el caso que estamos tratando un solo modelo de mujer. Pero el caso de la mujer que estamos analizando y los casos de otras mujeres que he podido encontrar en el psiquiátrico, nos demuestran que los comportamientos de las mujeres no estaban siempre dentro de los límites que se les marcaban. Así, la España de la década de 1940 nos demuestra que no existe un axioma de la mujer en general o de la experiencia típica de la misma (Graham 2010: 183). Había subversiones al modelo ideal, y tenerlos en cuenta nos abre la puerta a ver los comportamientos y las vivencias de las mujeres ingresadas en psiquiátricos desde el punto de vista de la resistencia. En las obras literarias de mujeres escritoras encerradas en psiquiátricos se identifica, en muchas ocasiones, la locura de las mujeres con el refugio. Incluso hay casos en los que los psiquiátricos se ven como el lugar donde sentirse protegidas de la sociedad patriarcal; una manera de estar fuera de las labores de casa. Es por esto por lo que la locura puede llegar a verse como una actitud resistente hacia el rol establecido. Debo detallar que, cuando me refiero a la resistencia, me acerco a ella desde el punto de vista que plantea la antropóloga feminista Dolores Juliano. Según Juliano (1992: 12), las mujeres nunca han sido sumisas ni pasivas: 
"Se producen aceptaciones y adaptaciones [...] pero también cuestionamientos implícitos y explícitos" (Juliano 1992: 22).

En el caso de Carole, como era una persona de clase alta, no tenía que hacer las labores de casa, pero había comportamientos que debía cumplir: ser sumisa, no tener deseo sexual y ser cuidadora, entre otros. Su comportamiento es contradictorio para la moral contemporánea: decía que quería ver a su hijo y sus hijas, que los/las quería y que quería estar con él y ellas, rechazaba a la persona que le había quitado la tutoría de sus hijas y, de la misma manera, mostraba el deseo de seguir viajando: "bring me alive and safely to Portugal. Once there I would like to continue my journey to New York".

Otro ejemplo de la práctica resistente de Carole es la utilización que hace de los idiomas. Aparte de castellano, hablaba inglés y francés. "Como habla en inglés no sé lo que dice" escribió una enfermera; o "como yo no comprendo lo que me quiere decir se echa una carcajada muy fuerte" decía otra. Carole sabía que si hablaba en otro idioma que no fuese castellano no iban a entender lo que decía; por lo tanto, podemos pensar que se sentía más libre cuando hablaba un idioma que era extraño para los/las que la rodeaban; es más, se puede interpretar como un modo de ponerse por encima de ellos/ellas y hacerles frente.

De todas formas, no solo utilizaba la palabra, también hacía uso del silencio que lo utilizaba, como el idioma, estratégicamente. Ella misma dice en una ocasión anteriormente mencionada: "Doblegarme y esperar a que llegue el día que usted pueda hablar". En ese sentido, y siguiendo lo que dice Lila AbuLughod (1990), el silencio también tiene un punto de resistencia y el silencio activo se puede considerar como resistencia activa:

Las violaciones del código tienen que ser entendidas como maneras de resistencia al sistema y desafío a la autoridad de aquellos/as que la representan y sacan beneficio de ella ${ }^{28}$ (Abu-Lughod 1990: 47).

Carole sabía cuándo tenía que hablar y cuándo tenía que callar, y entre esas dos opciones, hacía una utilización consciente de la palabra y el silencio, por lo menos en ciertas ocasiones.

Podemos interpretar como una actitud resistente también la costumbre que tenía Carole de tirar cosas al suelo. Leemos en una nota de una enfermera: "Tira al suelo la mesa y el desayuno". Podía ser una manera de romper

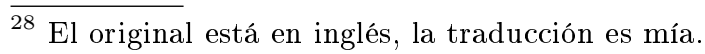


el orden del psiquiátrico por no estar contenta con su encierro, mostrando continuamente su enfado: "A los días de recibir la noticia de que le van a venir a buscar cambia completamente de carácter esta contentísima pensando van a llevarle a su país".

Desde un punto de vista más general, se puede añadir que la vida que llevaba Carole no era la que se les presuponía a las mujeres de aquella época: "I want to live a normal life, writing, reading, working and so on". Quería leer, escribir y trabajar, y esas acciones no eran las que se le suponían a la mujer ejemplar. La lectura, por ejemplo, era algo que se limitaba, en el caso de las mujeres, sobre todo si se les había diagnosticado una "enfermedad mental". En ese caso, se les "aconsejaba" que dejasen o limitasen esa costumbre bajo el argumento de que les aumentaba aún más confusión mental.

Hay que añadir que la locura, en general, se ha visto como una actitud resistente en más de una ocasión. Emily Martin (2008) considera la manía como algo que los seres humanos crean activamente y no como una situación que domina a la persona: "Si los actos, aunque sean espontáneos, muestran cierto carácter deliberado, ¿por qué no podríamos considerarlos racionales?" (Martin 2008: 135). Precisamente, Allice Bullard habla en ese mismo sentido en su artículo The truth in madness: Colonial doctors and insane women in French North Africa (Bullard 2001), señalando que las manías, las depresiones, etcétera, nos pueden dar información sobre los planes de las mujeres, sobre sus luchas para conseguir poder en la sociedad y en sus propias familias (Bullard 2001: 120). Pero habría que subrayar que hay muchos/as autores/as que no comparten esa idea de resistencia en la locura. Según ellos/ellas, las mujeres consideradas locas querían romper con los roles marcados y luchar contra la sociedad patriarcal (conscientemente o inconscientemente), pero no eligieron la "enfermedad mental". Consideran que detrás de la locura había señales resistentes y revolucionarias, pero no opinan que la locura fuera un instrumento para ello; entienden la locura como la manta que servía para tapar las diferentes patologías, actitudes y pensamientos que ponían en duda los roles tradicionales (Ruiz Somavilla y Jiménez Lucena 2003: 15).

Tapadera o no, Carole puso en tela de juicio el rol de mujer que planteaba el régimen franquista. Teniendo como punto de partida una idea $u$ otra, es decir, que la "enfermedad mental" fuese una consecuencia de la sociedad o fuese un mecanismo creado para hacerle frente a ella, las dos situaciones nos demuestran el sufrimiento de las personas que vivían en esas condiciones, y las dos situaciones pondrán en jaque el rol hegemónico al que se tenían que 
someter. Por supuesto, que la locura en muchas ocasiones no sería algo elegido conscientemente, pero ver una mera victimización en ella no nos deja captar en su totalidad lo que a esas personas les estaba ocurriendo.

La agencia individual, su voluntad de cambio y las estrategias que utilizaron para maniobrar dentro de sus circunstancias, se unieron al desafío de las normas, a veces de manera evidente, a veces de manera velada, que formó parte de las prácticas de disidencia sutil pero constante que tuvieron lugar en la posguerra (Murillo 2013:16).

Si vemos a las mujeres ingresadas en instituciones psiquiátricas como personas vacías de voluntad y agencia, las estaremos tratando como una masa uniforme que actuaba a la vez y en el mismo sentido. Ante esa visión, este artículo quiere concluir que: aflorar la contradicción, la resistencia y la ambivalencia es absolutamente necesario si queremos hacer una lectura más amplia de todo esto.

\section{Bibliografía}

1. Abad, I. (2009). Las dimensiones de la "represión sexuada" durante la dictadura franquista. In Rodrigo, J. \& Ruiz, M.Â. (coord.), Dossier: Guerra civil: las representaciones de la violencia (pp. 65-86). Jerónimo Zurita.

2. Abu-Lughod, L. (1990). The romance of resistance: Tracing transformations of power through Bedouin women. American ethnologist, 17(1): 41-55.

3. Altuna Etxeberria, M. \& Aranburu Zinkunegi, M. (2012). Ibiltari behartuetatik hegan egiteaz oroitu zirenetara: Genero femeninoaren eraikuntza lehen frankismoan Tolosan). Tolosako Udalaren Berdintasun Saila, II. Ikerketa Beka (sin publicar).

4. Appignanesi, L. (2008). Mad, Bad and Sad. A history of women and the mind doctors from 1800 to the present. Reino Unido: Hachette.

5. Barrachina, M.A. (2003). Discurso medico y modelos de género. Pequeña historia de una vuelta atrás. In Nielfa, G. (ed.), Mujeres y hombres en la España franquista: sociedad, economía, cultura, política (pp. 67-94). Madrid: Universidad Complutense.

6. Bullard, A. (2001). The truth in madness. South Atlantic Review, 66(2): 114132.

7. Echeverría, J. (1948). Notas para un estudio psiquiátrico de Guipúzcoa (En el cincuentenario de la apertura de la Casa de Salud de Santa Águeda). Donostia: Diputación de Gipuzkoa. 
8. González Pérez, T. (2009). Los programas escolares y la transmisión de roles en el franquismo: la educación para la maternidad. Revista de Pedagogía, 61(3): 93-106.

9. Graham, H. (2010). Gender and the State: Women in the 1940s. In Spanish Cultural Studies (pp. 182-195). New York: Oxford University Press.

10. Juliano Corregido, D. (1992). El juego de las astucias: mujer y construcción de modelos sociales alternativos. Madrid: Horas y Horas.

11. López Velasco, R. (2010). Usurbilgo Sendategia. Iragana eta oraina. LasarteOria: Usurbilgo Sendategia.

12. Martin, E. (2008). Experiencia interior y trabajo de campo etnográfico. In Bullen, M. \& Diez Mintegui, C. (coord), Retos teóricos y nuevas prácticas, XI (pp. 117-139). EHU: Antropologia kongresua.

13. Medina Doménech, R. (2013). Ciencia y sabiduría del amor: una historia cultural del franquismo (1940-1960). Madrid: Iberoamericana.

14. Moraga García, M.Á. (2008). Notas sobre la situación jurídica de la mujer en el franquismo. Feminismo/s, 12: 229-252.

15. Murillo Aced, I. (2013). En defensa de mi hogar y mi pan. Estrategias femeninas de resistencia civil y cotidiana en la Zaragoza de posguerra, 1936-1945. Zaragoza: Universidad de Zaragoza.

16. Piérola Narvarte, G. (2000). Aspectos del discurso moral de la Iglesia sobre la población femenina navarra del Franquismo. Gerónimo de Uztariz, 16: 43-55.

17. Ruiz Somavilla, M.J. \& Jiménez Lucena, I. (2003). Género, mujeres y psiquiatría: una aproximación crítica. Frenia, 3: 7-29.

18. Terradas i Saborit, I. (1992). Eliza Kendal. Reflexiones sobre una antibiografía. Barcelona: Publicacions dt'Antropologia Cultural, Universitat Autònoma de Barcelona.

\section{Author's Biodata}

Itxaso Martin Zapirain es doctora en Antropología (2015) con la tesis titulada Eromena, azpimemoria eta isiltasuna(k) idazten: hutsune bihurtutako emakumeak garaiko gizartearen eta moralaren ispilu (Escribiendo la locura, la submemoria y los silencios: mujeres hueco como espejo de la sociedad y la moral). Máster en Estudios Feministas y de Género (UPV, 2011). Licenciada en Antropología cultural y Social (UPV-EHU, 2010) y Comunicación Audiovisual (UPV-EHU, 2003). Ha publicado la novela Ni, Vera (Elkar, 2012) basada en la historia de su bisabuela que estuvo ingresada en un psiquiátrico de Gipuzkoa de 1935 a 1986. 